\title{
Internal pore measurements on macroperforate planktonic Foraminifera as an alternative morphometric approach
}

\author{
Monica Constandache $\cdot$ Florence Yerly • \\ Silvia Spezzaferri
}

Received: 24 January 2013/Accepted: 29 May 2013/Published online: 16 November 2013

(C) Swiss Geological Society 2013

\begin{abstract}
Because of the lack of genetic control on extinct species, the morphologic approach remains the only way of identifying fossil Foraminifera. In addition to comparative description of gross shell morphology, morphometry became more important in recent years and was extended to encompass the ultrastructure of the shells. In particular, some studies focused on porosity, as determined by the pore diameters plotted against the number of pores per given surface. However, taking into account the poor preservation and recrystallization, which often affects and characterizes fossil specimens, and/or the deficiencies connected to the interpretation of scanning electron microscope images, pore measurements are often distorted, limited in number and lacking precision, and thus unreliable. We demonstrate that, by measuring the pores from inside the shell and individually, it is possible to obtain numerous and precise data either on an individual basis or for statistical purposes. This study also suggests that in the Early Miocene Globigerinoides, which is generally strongly susceptible for dissolution, the dissolution proceeds from the external towards the internal side of the shell.
\end{abstract}

Editorial handling: K. Grimm \& D. Marty.

Electronic supplementary material The online version of this article (doi:10.1007/s00015-013-0134-8) contains supplementary material, which is available to authorized users.

M. Constandache $(\bowtie) \cdot$ S. Spezzaferri

Department of Geosciences, Earth Sciences, University of

Fribourg, Chemin du Musée 6, 1700 Fribourg, Switzerland

e-mail: monica.constandache@unifr.ch

F. Yerly

Department of Mathematics, University of Fribourg,

Chemin du Musée 23, 1700 Fribourg, Switzerland
Keywords Planktonic Foraminifera - Ultrastructure · Morphometry · Porosity · Internal shell measurements · Analytical methods $\cdot$ SEM

\section{Introduction}

Planktonic Foraminifera are a group of zooplankton with a biomineralized shell having a latitudinal distribution ranging from the poles to the equator (Bé et al. 1977; Hemleben et al. 1989). Due to their potentially undisturbed deposition on the sea floor and generally good preservation, as well as to the large and still expanding collection of data going back to the 1970s and resulting from the various deep sea drilling programs (DSDP, ODP, IODP), they are excellent biostratigraphic index fossils.

In spite of their great stratigraphic importance, some of the fossil planktonic Foraminifera lineages are poorly known, especially at the beginning of their ranges. However, their taxonomy is primordial to ascertain lineages and to use them as an efficient biostratigraphical tool in the fossil record where no genetic control is available for most of the extinct species.

Historically, taxonomic distinction of the Foraminifera was based primarily on the gross shell morphology, and therefore the morphospecies concept was used. The increasing use of SEM imagery on a large scale allowed Bé (1968) and Bé et al. (1969) to focus their investigation on the wall texture to better understand the shell growth patterns. This approach is based on the assumption that the wall texture reflects basic growth habitats for genera and even species (Bé 1968). He also attempted to link wall texture and distribution patterns of Foraminifera over latitudinal belts. As a consequence, the potential of wall 
textures at genus and species level but also as climatic indicators was recognized (Bé 1968).

Bé (1968), who pioneered this approach, restricted his work to recent planktonic assemblages. He focused on two parameters defining shell porosity: the number of pores on a given shell surface $(25 \mu \mathrm{m} \times 25 \mu \mathrm{m})$ plotted against the pore diameter. His approach yielded promising results not only as a tool for discriminating genera and in some cases even species (Bé 1968) but also to relate shell porosity to various climatic belts. Several researchers extended and applied this approach on porosity of living Foraminifera to other environmental aspects such as the bottom water oxygen content (e.g., Kuhnt et al. 2012). Porosity studies were also extended to the fossil record, and used, in particular, for palaeoceanographic reconstruction (Fisher et al. 2003; Fisher 2003), or as a more refined criterion to define wall textures (Hemleben and Olsson 2006).

Bé (1968) noted that pores should be measured on the internal side of the shell, as the outer side is often obscured. In particular in the fossil record, Foraminifera are frequently poorly preserved (e.g., Spezzaferri 1995; Herrero and Canales 2002), and this seriously hampers the identification of species and even more a precise analysis of the outer shell ultrastructure. Indeed, in many cases, calcification (e.g., Hemleben et al. 1989; Caron et al. 1990), recrystallization (e.g., Sexton and Wilson 2009), test dissolution (Hemleben and Olsson 2006; Schiebel et al. 2007; Johnstone et al. 2010; Nguyen et al. 2011), diagenetic alteration (Hemleben and Olsson 2006) considerably affect the ultrastructure including pore diameters, and even the general test morphology. Additionally, the curvature of the shell may also hinder the precise assessment of the pore size, especially when associated with a thick shell (Bé 1968; Hemleben et al. 1989). Artefacts related to SEM photography (Castle and Zhdan 1997; Marinello et al. 2008) may also prevent a precise estimation of the pore dimensions.

While not all the researchers who conducted this kind of research in the fossil record specify if measurements were taken on the internal or the external side of the test, some do mention that they collected the data internally (e.g., Frerichs and Ely 1978; Fisher et al. 2003). In these latter cases, data are analysed with various software packages (e.g., SPSS Sigmascan) that measure the overall porosity. However, in some cases, it is necessary to know the dimensions of individual pores (e.g., in case of high intra-individual variability, or when only very small test fragments are available). The major purpose of this study is to better assess pore morphometry, and therefore, we present a new approach where one-by-one measurements of pores are taken from the inside of the test.

\section{Materials and methods}

This study is based only on macroperforate planktonic Foraminifera with cancellate wall texture. Genera with smooth or with microperforate wall texture are not included in this study. These latter types of wall textures are problematic, notably because of differential internal test dissolution (Schiebel et al. 2007). Thus, they require other approaches, and are not considered here.

Our study focuses on the inception of the lineage of the genus Globigerinoides. Internal pore morphometry was performed on specimens from DSDP cores from DSDP Site (Hollister et al. 1972; Worzel et al. 1973; Edgar et al. 1973a; Edgar et al. 1973b; Barker et al. 1983; Moore et al. 1984), and ODP cores from ODP Site (Barron et al. 1989), all spanning zones P22 to N5 and exceptionally N6 (Catapsydrax stainforthi Zone sensu Bolli 1966; Bolli et al. 1985).

We investigated shell porosity on SEM images taken on the internal shell and compared them with images of the external shell surface. Magnification ranged from 1,200 to $1,500 \times$, exceptionally up to $6,000 \times$. Only adult specimens were chosen. Measurements were performed on the last chamber of each specimen, except in cases when it was a kummerform. After having taken images of the external shell surface, the ultimate chamber of each individual was broken manually under the binocular microscope, using a steel needle microlance with an external diameter of $0.3 \mathrm{~mm}$, attached to a plain medical syringe. The fragments (1-3 for each individual) were fixed with the concave inner side upwards and prepared for the SEM with a gold coating of $40 \mathrm{~nm}$. Pictures were taken with the viewing angle normal to the centre of the image in order to avoid pore distortion (Bé 1968). For the same reason, diameters were

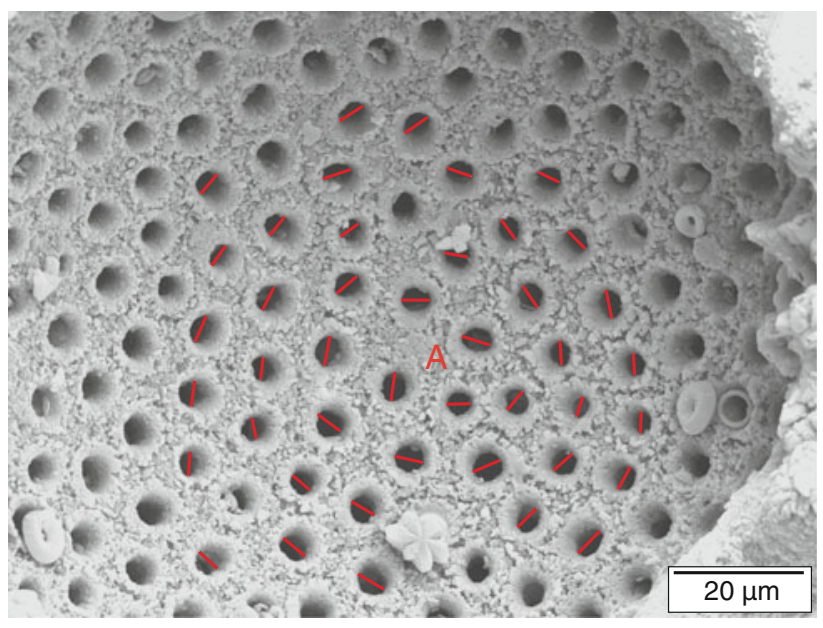

Fig. 1 Diameters of the pores are measured tangentially around the central zone (zone A, pores marked with red diameters) where the incoming electron beam is normal to the pores 
measured tangentially in a restricted circular area around the central point of the image (Fig. 1). When the pores were not circular (but elliptic), the "longest" diameter was systematically measured.

Two hundred sixty-seven specimens were selected, and a total of 535 images have been obtained. In contrast to pore measurements performed externally, where only a few diameters could be quantified, a very high number of measurements from the inside of the shell was obtained (up to 189 measurements per specimen, depending on the quality of the images). However, such an extensive data set does not considerably improve the precision, as a minimum of 30 measures is generally sufficient to obtain a normal approximation (Ross 2004). We have reduced our investigation to two subsets, one including 73 specimens (for the study of intra-individual pore variability) and the other including 58 specimens (for the comparison between the external and internal pore measurements). For each specimen we computed the mean value of all the measurements obtained, and we consider this value to be representative of the pore-dimension.

\section{Results and discussion}

In the fossil record dissolution and/or recrystallization often modify the external surface of the foraminiferal wall texture (Hemleben et al. 1989; Thunell 1976; De Vernal et al. 1992; Kotler et al. 1992; Green et al. 1993; Lohmann 1995). Dissolution of the test, in particular, seems to occur while empty planktonic shells sink through the water column, mostly in the photic zone (Milliman et al. 1999; Schiebel 2002; Schiebel et al. 2007), or while they reach the sea floor and become part of the sediment (Broeker and Clark 2001, 2002). This process may induce an important weight loss as compared to the initial weight of the test (Broeker and Clark 2001).

Calcite overgrowth due to gametogenic calcification (Hemleben et al. 1989) may also cover the outer surface of shells preventing a correct estimation of the pore diameter. It may also fill pore channels, partly or entirely (Figs. 2a-c, 3ab). This occlusion of the pores from the outside is one of the most relevant features we encountered and it has been observed in about $95 \%$ of our images. Indeed, only about $5 \%$ of all images taken from the outside of the test yielded an accurate perception of a "clean" pore diameter (Fig. 4a-b).

Artefacts related to the SEM and/or linked to visual perception may distort the process of measuring the external pore diameters (Castle and Zhdan 1997; Marinello et al. 2008). The diameter seen through a pore channel, which is more or less sealed, may be difficult to assess as "real" (i.e. as seen through a "clean" pore channel), as it is impossible to estimate the degree to which the pore filling

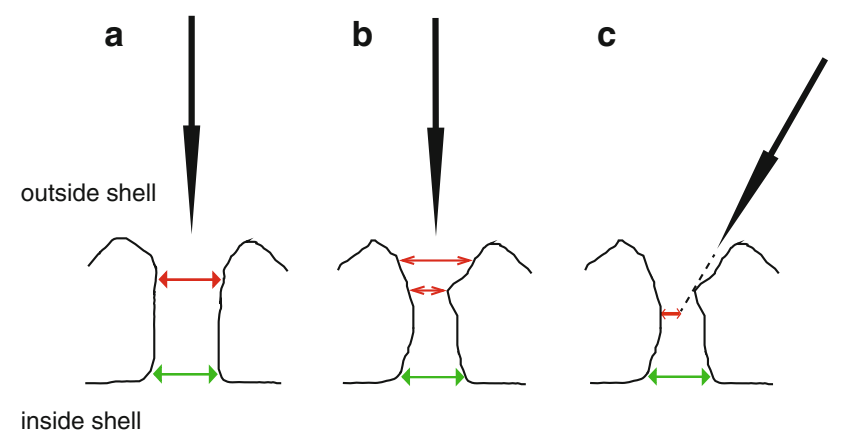

Fig. 2 Arrow electron beam. The inside and outside of the shell are indicated for $\mathbf{a}, \mathbf{b}, \mathbf{c}$. In green the "real" diameter, as measured from the inside of the test. a Cross section through pore: what is perceived in the SEM image, in red, is equal to the real diameter. b Differently perceived diameters, none of which is corresponding to the real diameter (in green). c Diameter dimension biased (in red) by an inclined incidence of the electron beam

biases the measurement (see Fig. 4). Additionally, an image may undergo subjective interpretation connected to visual perception. Qualitative tests performed on different persons (scientists) showed that their interpretation of the same image may be different (Fig. 5).

Moreover, the convex curvature of the shell surface associated with the wall thickness induces a radial divergence of pores- the thicker the wall, the stronger the resulting distortion (Bé et al. 1969, 1973) — and this also reduces the usable part of the image to its central part, where the direction of the electron beam is normal to the shell surface (Marinello et al. 2008; see also Fig. 4a). If the electron beam is not perpendicular, the pore diameter may sometimes be inferred (e. g. if the internal margin of the channel can be seen), but the result is not fully reliable. Therefore, such an approach of pore diameter estimation should be avoided.

Taking into account these practical limitations, the overall number of valid measurements obtained from the outside of the shell is low (three to five values on average, but often only one or two), and this does not allow any assessment with statistical confidence. Considering the relatively high pore variability (Fig. 6), which is readily recorded, individual values as well as averages calculated on few measurements, should definitely be avoided and mean (or median) values of at least 30 diameters (Ross 2004) should only be used.

Indeed, intra-individual variability in size and shape of the pores in planktonic Foraminifera has already been recognized, in general as a morphological indication of cryptic speciation (Huber et al. 1997; Morard et al. 2009), sometimes with a clear a bi-modal distribution (Morard et al. 2009). The genus Globigerinoides at the beginning of its range in the Late Oligocene-Early Miocene (Spezzaferri 1994, 1995) also displays an important amount of variability even at the species level (see Fig. 6; Table 1, ESM 1 ), which is at the moment poorly understood. 

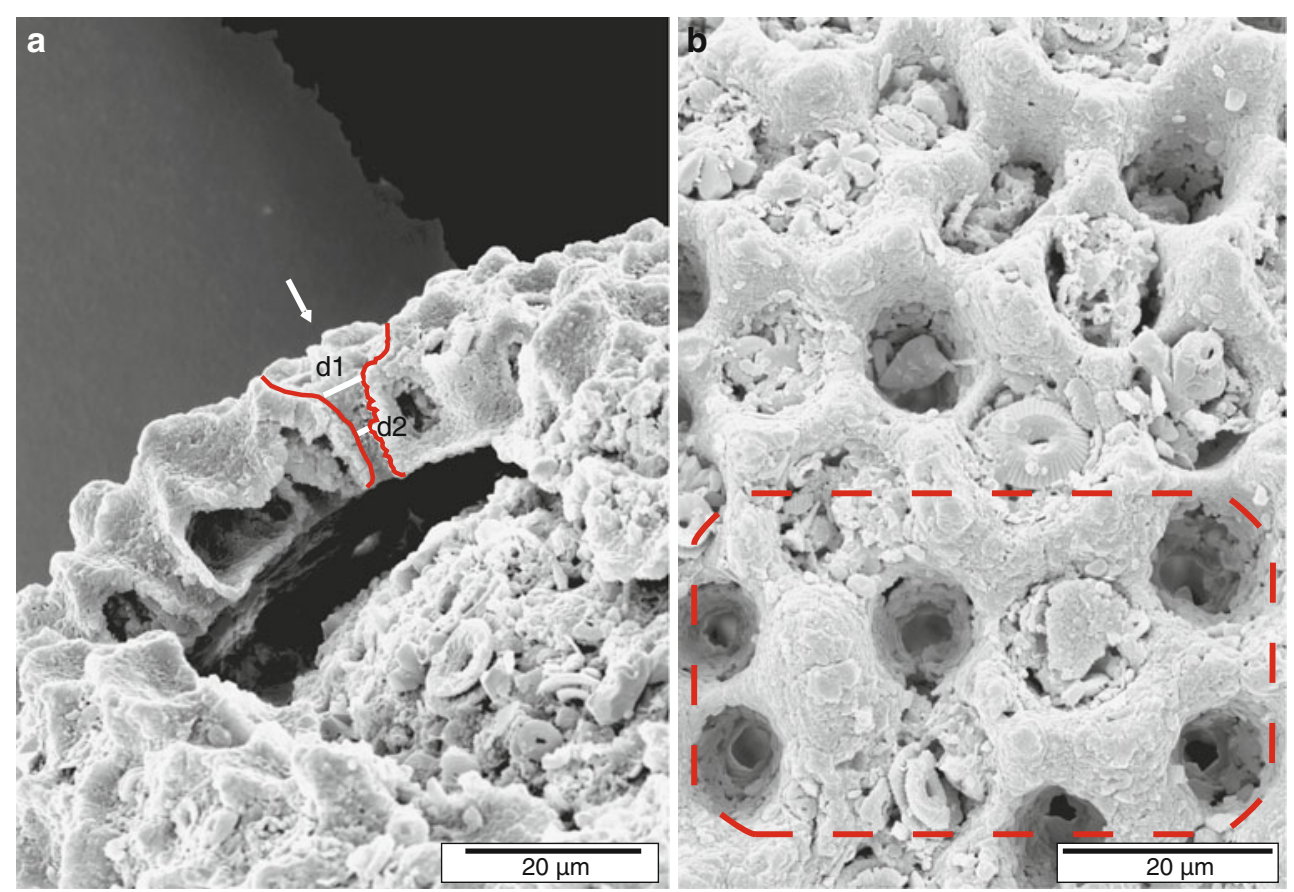

Fig. 3 Pores clogged by calcite infillings. a Cross section through the test wall. $d 1$ and $d 2$ are two different diameters, none of which corresponds to the real diameter that is only visible on the inside of the shell. $\mathbf{b}$ External view of the shell shown in a

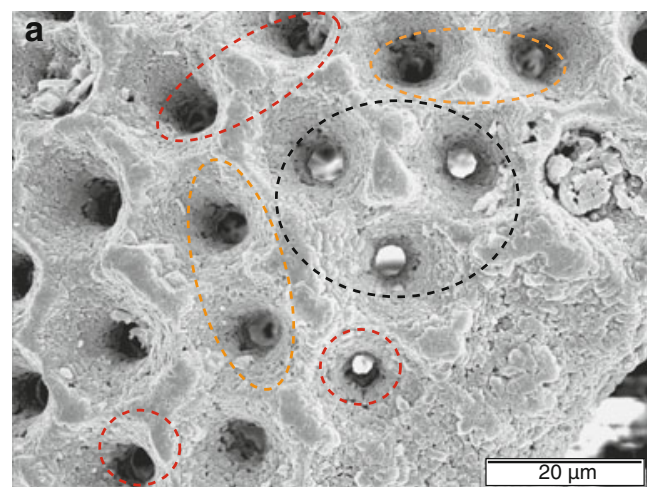

Fig. 4 Different degrees of biases, due to the inclined incidence of the electron beam and affecting the perception of pore diameters. a Inside of black dotted line reliable measurements, inside of orange dotted line measures may be conjectured, inside of red dotted line

In order to assess this intra-individual variability we took a closer look at the mean diameters of a chosen set of 73 specimens (Table 1, ESM 1) on which we performed internal measurements, following the procedure described above. We first computed the variation coefficient on this data by normalizing the standard deviation $(\sigma)$ around the mean $(\mu)$; it amounts to $33.2 \%$. Under the hypothesis of a normal distribution (which is assumed here), the interval $(\mu-2 \sigma, \mu+2 \sigma)$ contains $95 \%$ of the data. In our case, $\sigma$ is approximatively $0.33 \mu$, thus the interval is $(0.34$, $1.66 \mu)$. We see that he spreading around the mean is high (the length of the interval is $1.32 \mu$ ). A Welch's test (Johnson and Welch 1940) was performed on this data to

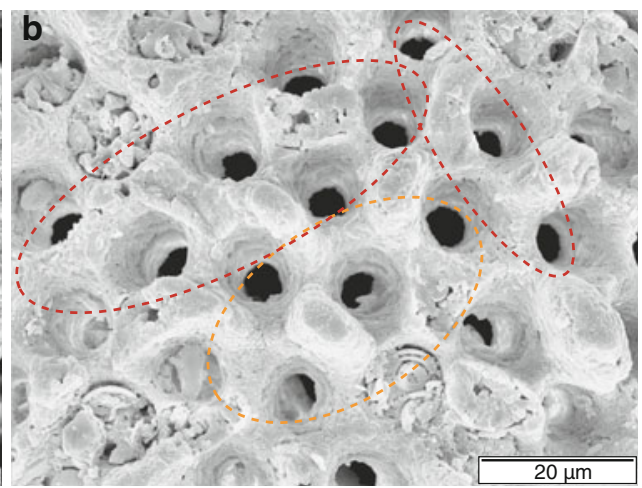

measurements should not be used. b Inside of red dotted line images unreliable because of radial divergence. In the orange zone even if the pore is partially infilled, the full length of the diameter can be perceived

determine if the variation coefficient is greater than a $10 \%$ value, which is a reasonable variability. The test shows that our variation coefficient is significantly larger than $10 \%$, the $p$ value is almost 0 , which means that the variability is statistically significant.

Another way to compute the variability without assuming a normal distribution is to deal with the interquartile range, which is the quantile at $95 \%$ minus the quantile at $5 \%$, and it represents the length of the interval around the median, encompassing $90 \%$ of the data (i.e. $90 \%$ of the 73 specimens). This interquartile range amounts to $0.42 \mathrm{~nm}$; compared to the median it amounts to approximately $115 \%$. This implies that the spreading of 
the data around the median is very high, its range being even larger than the value of the median itself. We see that both approaches convey the same information, i.e. that the

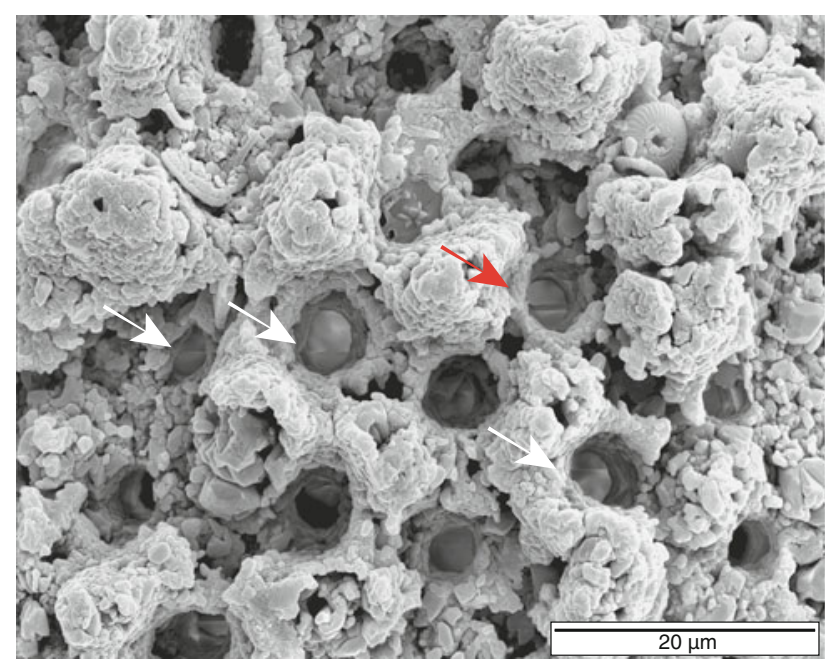

Fig. 5 Differential perception/interpretation of pore images. Red arrow crystal clogging a pore. White arrows possible artefacts of the SEM photography

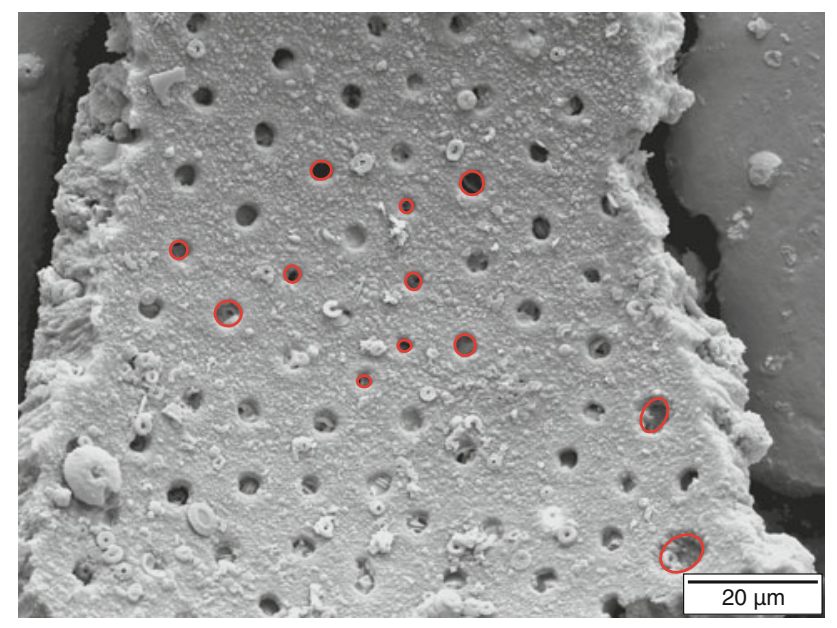

Fig. 6 High variability of pore diameters in a single specimen specimens of the sample analysed exhibit an important intra-individual variability.

These results confirm and justify the fact that it is essential to acquire an important number of measurements $(\geq 30)$ to assure that the empirical values (of the pore diameters, in our case) are the closest possible to the "true" values, and to allow a statistical treatment. The lack of a significant number of measurements is an important drawback, that can only be avoided by using internal pore measurements. Indeed, the internal side of the shells is less affected by recrystallization, and in most cases pores are not filled and/or covered by external material (e.g., nannofossils) (Fig. 7a-b).

In previous studies (Huber et al. 1997; Fisher et al. 2003; Morard et al. 2009) the overall porosity was treated on a statistical basis, using different softwares such as SPSS Sigmascan Pro, OPTIMAS and others. It is worthwhile noting here that porosity (percentage of pore surface per given surface) rather than pore concentration (number of pores per given surface) should be used for temperature or palaeoceanographic reconstructions, as the same porosity value can be achieved either through a large number of small pores or a small number of large pores (Fisher et al. 1972, 2003). For the treatment of the images the above mentioned software packages proceed by contrasting, i.e., they blacken the grey values (representing the voids in the surface, i.e., the pores of the shell) that exceed a given grey-value threshold. In the next step the programs calculate the overall "black" (=pore) surface compared to the surface of the whole image. The value thus obtained represents an average porosity, which can be extended to the whole shell surface. However, this method requires a correction phase to remove biases due to the electronic image analyser (Morard et al. 2009).

In contrast to the above method, the morphometric approach that we present in this study measures the pores internally and individually. As this approach is direct, with no distortion of the pores (because of reduced inner recrystallization the image is "clean"), with no bias due to either shell thickness or radial divergence, and with no
Fig. 7 The same specimen in external view with clogged pores (a) and internal view (b) of its test
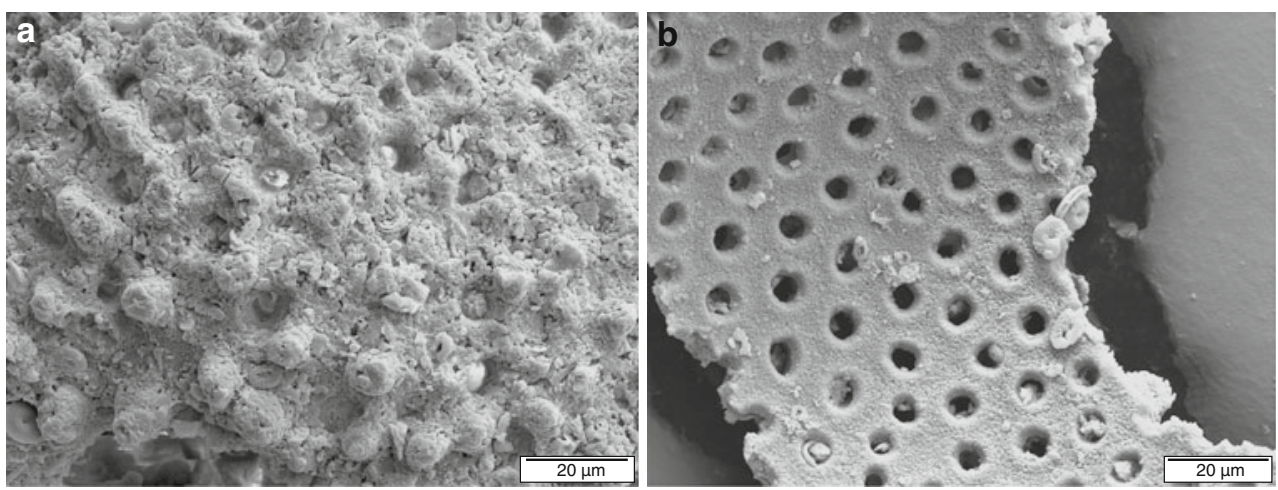
approximation (no perceptive distortion), the assessment of the inner pores requires no further correction.

We tested the validity of this new approach on a set of 58 individuals by comparing internal and external pore measurements of the same individual (Table 2, ESM 2). The aim was to check if some systematic correlation possibly existed between these differently acquired values (i.e., if externally measured values were systematically smaller than the ones measured from the inside). If such a trend existed, some kind of conversion index between external and internal pore sizes could be calculated to "normalize" external measurements-which are easier to obtain-and convert them to "real" ones.

However, no such trend is present (Fig. 8; Table 2, ESM 2). If $12 \%$ of the individuals ( 7 out of 58) (see Fig. 8 , inside of the red box) exhibit internal and external values that are comparable, that is that the difference between the internally and externally acquired values is "small", $<0.065 \mu \mathrm{m}$, no correlation can be observed for the remaining $78 \%$ ones: while for half of them $(43 \%)$ internal measurements are larger than external ones (their difference $>0)$, for the other half $(45 \%)$ it is quite the opposite (the internal ones are smaller than the external ones). The values are randomly distributed (see Fig. 8). Thus no conversion index could be calculated and external measures were excluded from the data set.

Various researchers have noted that planktonic Foraminifera may display inner dissolution of their calcitic tests, possibly due to a low $\mathrm{pH}$ within this internal microenvironment (Schiebel et al. 2007). Dissolution, however, (1) works selectively (Dittert et al. 1999) and (2) was studied mostly on recent microperforate specimens (Schiebel et al.

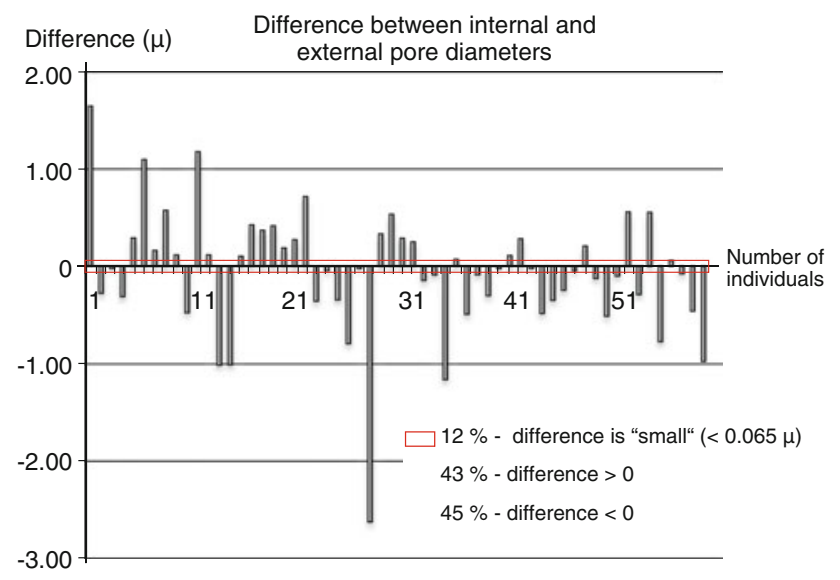

Fig. 8 The figure plots the difference between internal and external values. If this difference is $>0$, it means that the internal pore values are larger than the external ones; conversely, when it is $<0$, the externally obtained values are higher. Only $12 \%$ of the measurements (inside red box) are comparable (i.e., their difference is "small", $<0.065 \mu \mathrm{m})$. The values are randomly distributed and no trend appears
2007; Schiebel 2013, pers. communication). However, no signs of dissolution were observed in the inner part of the shells of any of the studied specimens possessing a macroperforate cancellate and honeycomb Globigerinoides type wall texture (Spezzaferri 1994). Therefore, we suggest that (1) although Globigerinoides are among the Foraminifera most sensible to dissolution (Spezzaferri 1995), dissolution affects their shell from the outside towards the inside, and that (2) the weight loss observed by Broeker and Clark (2001, 2002) and Lohmann (1995) results from dissolution of the external overall test layers, rather than by enlargement of the pores from the inside of the shell.

\section{Limitations}

Although this method produces reliable results and large data sets, it has one limitation. It can be applied only to samples where a sufficient number of specimens that can be broken is available. Evidently it can not be applied on type specimens that have to be preserved for comparison.

Time could also be expected to be a limitation. Breaking of the tests and fixing them on the SEM stub is somewhat time consuming, but more than time, this demands a certain delicacy in manipulating the broken shells, which is readily acquired through training. The SEM imaging of the broken tests requires the usual time for photographing. However, as the whole process does not necessitate further corrections and yields high quality images, this favourably compensates the extra time spent on photographing.

\section{Conclusions and outlook}

The applications of this new measuring method are multiple. In addition to its first objective (porosity analysis applied to species distinction and as an environmental index) it allows, more specifically, the assessment of intraindividual pore variability, a quantitative comparison between internal and external pore measurements, as well as the quantification of the pore growth during ontogeny.

So far, the majority of pore measurements used for morphometry were performed on SEM pictures either of the outer shell of planktonic Foraminifera (which produce invalid data) or were processed by an overall analysis of the porosity, when measured from the inside. We demonstrate here that the external pore measurements are not reliable and should not be used for quantitative studies. We also propose an alternative method of analysing pores from the internal side of the test and on an individual basis.

This method is direct, easy to perform and offers three important advantages: (1) the measurements are more accurate as recrystallization affects the inner side of the 
shell at a lesser degree than the outside; (2) as opposed to studies on overall porosity, it allows to acquire very accurate data for each pore, and this, in turn, permits to calculate overall porosity on a more precise basis and (3) it provides an important number of data for statistical purposes. Given the important variation of intra-individual pores, statistical approaches should preferentially be used, and approaches based on a few measurements only (e.g., external approach) should be avoided. Finally, this study reveals that although Globigerinoides is dissolution susceptible, this process seems to affect their shell progressively from the outside towards the inside of the test.

Acknowledgments The authors would like to thank the DSDP and ODP programs for providing sample material. This paper greatly benefited from constructive and careful comments by R. Schiebel (UNI Angers) and an anonymous reviewer. The authors are indebted to R. Olsson (Rutgers UNI, USA) and F. Jorissen (UNI Angers) for stimulating discussions on the scope of this work and the applied methodology. We would also like to thank Christoph Neuruhrer (UNI Fribourg) for technical assistance with the SEM work.

\section{References}

Barron, J., Larsen, B., et al. (1989). ODP Site 744. Initial reports of ocean drilling program ODP. 119, 477-504.

Barker, P.F., Carlson, R.L., Johnson, D.A., et al. (1983). DSDP Site 516F (Rio Grande Rise). Initial reports of deep sea drilling project. 72, 155-338. doi:10.2973/dsdp.proc.72.105.1983.

Bé, A. W. H. (1968). Shell porosity of recent planktonic Foraminifera as a climatic index. Science, 161, 881-884. doi:10.1126/science. 161.3844.881.

Bé, A. W. H., Harrison, S. M., \& Lott, L. (1973). Orbulina universa d'Orbigny in the Indian Ocean. Micropaleontology, 19, 150-192.

Bé, A. W. H., Hemleben, Ch., Anderson, O. R., Spindler, M., Hacunda, J., \& Tuntivate-Choy, S. (1977). Laboratory and field observations of living planktonic Foraminifera. Micropaleontology, 23, 155-179.

Bé, A. W. H., Jongebloed, W. L., \& McIntyre, A. (1969). X-ray microscopy of recent planktonic Foraminifera. Journal of Paleontology, 43, 1384-1396.

Bolli, H. M. (1966). The planktonic Foraminifera in well Bojonegoro1 of Java. Eclogae Geologicae Helvetiae, 59, 449-465.

Bolli, H. M., Saunders, J. B., \& Perch-Nielsen, K. (1985). Plankton stratigraphy. Melbourne: Cambridge Earth Science Series.

Broeker, W., \& Clark, E. (2001). An evaluation of Lohmann's Foraminifera weight dissolution index. Paleoceanography, 16, 531-534. doi:10.1029/2000PA000600.

Broeker, W. S., \& Clark, E. (2002). Carbonate ion concentration in glacial-age deep water of the Caribbean Sea. Geochemistry, Geophysics, Geosystems, 3, 1-14. doi:10.1029/2001GC000231.

Caron, D. A., Anderson, O. R., Lindsey, J. L., Faber, W. W., \& Lin Lim, E. E. (1990). Effects of gametogenesis on test structure and dissolution of some spinose planktonic Foraminifera and implications for test preservation. Marine Micropaleontology, 16, 93-116. doi:10.1016/0377-8398(90)90031-G.

Castle, J. E., \& Zhdan, P. A. (1997). Characterization of surface topography by SEM and SFM: problems and solutions. Journal of Physics D: Applied Physics, 30, 722-740. doi:10.1088/00223727/30/5/004.

De Vernal, A., Bilodeau, G., Hillaire-Marcel, C., Kassou N. (1992). Quantitative assessment of carbonate dissolution in marine sediments from foraminifer linings vs shell ratios: Davis Strait, northwest North Atlantic. Geology, 20, 527-530. doi:10.1130/ 0091-7613(1992)020<0527:QAOCDI >2.3.CO;2.

Dittert, N., Baumann, K.-H., Bickert, T., Henrich, R., Huber, R., Kinkel, H., et al. (1999). Carbonate dissolution in the deep-sea: methods, quantification and paleoceanographic application. In G. Fischer \& G. Wefer (Eds.), Use of proxies in paleoceanography (pp. 255-284). Berlin: Springer.

Edgar, N.T., et al. (1973a). DSDP Site 151. Initial reports of deep sea drilling project. 15, 301-329. doi:10.2973/dsdp.proc.15.106. 1973.

Edgar, N.T., et al. (1973b). DSDP Site 153. Initial reports of deep sea drilling project. 15, 367-406. doi:10.2973/dsdp.proc.15.108. 1973.

Fisher, C. (2003). Planktic foraminiferal porosity: a water mass proxy for latest Cenomanian paleoceanography, Greenhorn Sea, Western Interior USA and Canada. Cretaceous Research, 24, 633-651. doi:10.1016/j.cretres.2003.07.002.

Fisher, C. G., Sageman, B. B., Asure, S.E., Acker, B., Mahar, Z. (2003). Planktic foraminiferal porosity analysis as a tool for paleoceanographic reconstruction, Mid-Cretaceous Western Interior Sea. Palaios, 18, 34-46. doi:10.1669/08831351(2003)018<0034:PFPAAA $>2.0$.CO.

Frerichs, W. E. \& Ely, R. L. (1978). Test porosity as a paleoenvironmental tool in the Late Cretaceous of the Western Interior. Contributions to Geology, University Wyoming, 16, 89-94.

Frerichs, W. E., Heiman, M. E., Borgman, L. E., \& Bé, A. W. H. (1972). Latitudinal variations in planktonic foraminiferal test porosity: part 1. Optical studies. Journal of Foraminiferal Research, 2, 6-13.

Green, M. A., Aller, R. C., \& Aller, J. Y. (1993). Carbonate dissolution and temporal abundances of Foraminifera in Long Island Sound sediments. Limnology and Oceanography, 38, 331-345. doi:10.4319/lo.1993.38.2.0331.

Hemleben, C., \& Olsson, R. K. (2006). Wall textures of Eocene planktonic Foraminifera. In: P. Pearson, R. K. Olsson, B. T. Huber, C. Hemleben, W. A. Berggren (Eds.), Atlas of Eocene planktonic Foraminifera (pp. 47-66). Cushman Foundation Special Publication No. 41.

Hemleben, C., Spindler, M., \& Anderson, O. R. (1989). Modern planktonic Foraminifera. New York: Springer.

Herrero, C., \& Canales, M. L. (2002). Taphonomic processes in selected lower and middle Jurassic Foraminifera from the Iberian Range and Basque-Cantabrian Basin (Spain). Journal of Foraminiferal Research, 32, 22-42. doi:10.2113/0320022.

Hollister, C. D., et al. (1972). DSDP Site 98 (Northeast Providence Channel). Initial reports of deep sea drilling project. 11, 9-50. doi:10.2973/dsdp.proc.11.101.1972.

Huber, B. T., Bijma, J., \& Darling, K. (1997). Cryptic speciation in the living planktonic foraminifer Globigerinella siphonifera (d'Orbigny). Paleobiology, 23, 33-62.

Johnson, N. L., \& Welch, B. L. (1940). Application of the non-central t-distribution. Biometrika, 31, 362-389.

Johnstone, H. J. H., Schulz, M., Barker, S., \& Elderfield, H. (2010). Inside story: an X-ray computed tomography method for assessing dissolution in the tests of planktonic Foraminifera. Marine Micropaleontology, 77, 58-70. doi:10.1016/j.marmicro. 2010.07.004.

Kotler, E., Martin, R. E., \& Lidell, W. D. (1992). Experimental analysis of abrasion and dissolution resistance of modern reefdwelling Foraminifera: implications for the preservation of biogenic carbonate. Palaios, 7, 244-276. 
Kuhnt, T., Friedrich, O., Schmiedl, G., Milker, Y., Mackensen, A., Lückge, A. (2012). Relationship between pore density and bottom-water oxygen content in benthic Foraminifera. Deep Sea Research Part I: Oceanographic Research Papers. doi:10.1016/ j.dsr.2012.11.013.

Lohmann, G. P. (1995). A model for variation in the chemistry of planktonic foraminifera due to secondary calcification and selective dissolution. Paleoceanography, 10, 445-457. doi:10. 1029/95PA00059.

Marinello, F., Bariani, P., Savio, E., Horsewell, A., De Chiffre, L. (2008). Critical factors in SEM 3D stereo microscopy. Measurement Science and Technology, 19, doi:10.1088/0957-0233/ 19/6/065705.

Milliman, J. D., Troy, P. J., Balch, W. M., Adams, A. K., Li, Y.-H., \& Mackenzie, F. T. (1999). Biologically mediated dissolution of calcium carbonate above the chemical lysocline? Deep-Sea Research I, 46, 1653-1669. doi:10.1016/S0967-0637(99)00034-5.

Morard, R., Quillevéré, F., Escarguel, G., Ujiie, Y., De GaridelThoron, T., Norris, R. D., et al. (2009). Morphological recognition of cryptic species in the planktonic foraminifer Orbulina universa. Marine Micropaleontology, 71, 148-165. doi:10.1016/ j.marmicro.2009.03.001.

Moore, T.C., Rabinowitz, P.D., et al. (1984). DSDP Site 526A. Initial reports of deep sea drilling project. 74, 161-235. doi:10.2973/ dsdp.proc.74.103.1984.

Nguyen, T. M. P., Petrizzo, M. R., Stassen, P., \& Speijer, R. P. (2011). Dissolution susceptibility of Paleocene-Eocene planktonic Foraminifera: implications for palaeoceanographic reconstructions. Marine Micropaleontology, 81, 1-21. doi:10. 1016/j.marmicro.2011.07.001.
Ross, S. M. (2004). Introduction to probability and statistics for engineers and scientists (p. 624). USA: Elsevier Academic Press.

Schiebel, R. (2002). Planktic foraminiferal sedimentation and the marine calcite budget. Global Biogeochemical Cycles, 16, 13-1-13-21. doi:10.1029/2001GB001459.

Schiebel, R., Barker, S., Lendt, R., Thomas, H., \& Bollmann, J. (2007). Planktic foraminiferal dissolution in the twilight zone. Deep-Sea Research II, 54, 676-686. doi:10.1016/j.dsr2.2007.01. 009.

Sexton, P.F., \& Wilson, P.A. (2009). Preservation of benthic Foraminifera and reliability of deep-sea temperature records: importance of sedimentation rates, lithology, and the need to examine test wall structure. Paleoceanography, 24. doi:10.1029/ 2008PA001650.

Spezzaferri, S. (1994). Planktonic foraminiferal biostratigraphy of the Oligocene and lower Miocene in the oceanic record. An overview. Ph.D. Dissertation. Palaeontographia Italica, 81, $1-187$.

Spezzaferri, S. (1995). Planktonic foraminiferal paleoclimatic implications across the Oligocene-Miocene transition in the oceanic record (Atlantic, Indian and South Pacific). Palaeogeography, Palaeoclimatology, Palaeoecology, 114, 43-74. doi:10.1016/ 0031-0182(95)00076-X.

Thunell, R.C. (1976). Optimum indices of calcium carbonate dissolution, in deep-sea sediments. Geology, 4, 525-528. doi:10.1130/0091-7613(1976)4<525:OIOCCD $>2.0 . C O ; 2$.

Worzel, J.L., et al. (1973). DSDP Site 94. Initial reports of deep sea drilling project. 10, 195-258. doi:10.2973/dsdp.proc.10.111. 1973. 